\title{
Assessment of the Possibilities of B-Mode Ultrasonography in the Diagnosis of Atlanto-Axial Rotary Subluxation in Children
}

Abdullaeiv RY*, Sharmazanova EP, Voronzhev IA and Abdullaev RR

Department of Ultrasound Diagnostics, Kharkiv Medical Academy of Postgraduate Education, Ukraine

*Corresponding author: Abdullaeiv RY, Department of Ultrasound Diagnostics, Kharkiv Medical Academy of Postgraduate Education, Ukraine, Tel: +380972371919; Email: r.abdullaev@bk.ru

Rec Date: August 18, 2017; Acc Date: October 20, 2017; Pub Date: October 25, 2017

Copyright: (c) 2017 Abdullaev RY, et al. This is an open-access article distributed under the terms of the Creative Commons Attribution License, which permits unrestricted use, distribution, and reproduction in any medium, provided the original author and source are credited.

\begin{abstract}
Introduction: Among the traumatic injuries of atlantoaxial joint (AAJ) in children, a rotational subluxation in the C1-C2 segment is more common. The frequency of its occurrence in children less than 10 years varies from $34 \%$ to $73 \%$, in newborns this injury is the most frequent among all spinal injuries (upto 54\%). Radiography is the most common method for diagnosing rotational subluxation of the atlas, but has a number of limitations due to poor visualization of the soft tissue structures. MRI study is difficult to organize in newborns, in addition, this method is the most expensive. Ultrasonography is a cheap method, it allows using high-frequency sensors to provide visualization of the ligamentous apparatus and the spinal cord, which is very important in severe forms of trauma.
\end{abstract}

Objective: The aim of the study was to evaluate the possibilities of X-ray and ultrasound imaging methods in diagnosing the Atlanto-axial rotary subluxation (AARS).

Materials and methods: Our survey was based on 28 (45.2\%) newborns (group I) and 34 (54.8\%) children aged 4-6 years (group II) who were diagnosed with AARS as a result of birth and mechanical trauma, respectively. The comparative group (CG) comprised 50 children - of them 12 newborns, 15 - under the age of 1 year, 23 - at the age of 4-6 years. Everyone children were given radiography, ultrasound and only $12(19.3 \%)$ of them - MRI. Ultrasonographically were determined the structure of the transverse ligament (TL), the distance from the edge of the odontoid process (OP) to the inner lateral masses (LM: Lateral Masses) surface on both sides. The smallest value of this distance was denoted by D1, the largest by D2. Normally the difference between D2 and D1 did not exceed $0.5 \mathrm{~mm}$. The degree of asymmetry was estimated by the formula: D2-D1/D1 $\times 100 \%$, and normally ranged from $7 \%$ to $15 \%$.

Results: According to roentgenological data, in $40.9 \%$ of the newborns the ossification nucleus was in the anterior arc $\mathrm{C} 1$ and the width of the $\mathrm{x}$-ray gap of the anterior-atlas-axial joint was $1.5-2.0 \mathrm{~mm}$. The average distance between the LM at C1 level in newborns was $16.19 \pm 0.78 \mathrm{~mm}$, in children under 1 year of age it was $18.01 \pm 1.08$ $\mathrm{mm}$, at the age of $4-6$ years $-27.87 \pm 0.98 \mathrm{~mm}$. At the age of 1 to 3 years, the frontal and posterior arcs of the atlas are fused, its anterior tubercle is clearly pronounced and has the shape of an elongated oval with thickened end plates. Complete ossification of the tooth $\mathrm{C} 2$ and its fusion with the vertebral body occurs at the age of 4-6 years. In the lateral projection, apart from the Crucellus joint, the width of the retro-tracheal space was determined, which is $4.5 \pm 2 \mathrm{~mm}$ at the C1-C3 level, the posterior wall of the larynx and the trachea is normally even, parallel to the vertebral bodies. Ultrasonographically the thickness of the TL averaged $1.92 \pm 0.14 \mathrm{~mm}$ - in neonates, $2.31 \pm 0.17$ $\mathrm{mm}$ - in children under 1 year and $2.69 \pm 0.24 \mathrm{~mm}$ in children $4-6$ years. The thickness of the synovial bag (gap) between the OP and TL was normally more than $1.5 \mathrm{~mm}$. Cruciform ligament $(\mathrm{CL})$ on the echogram had a mediumlow echogenicity, an even contour and a thickness of 1.6 to $2.5 \mathrm{~mm}$, and an average of $1.83 \pm 0.17 \mathrm{~mm}$ in newborns, $2.14 \pm 0.15 \mathrm{~mm}$ in children 1 year and $2.35 \pm 0.21 \mathrm{~mm}-$ in $4-6$ years. On the axial ultrasonic section, the anteriorposterior dimension of the dural sac, the spinal canal (SC) and the spinal cord was determined. The sagittal size of the SC at the C1-C2 level in a newborn was $10.04 \pm 0.42 \mathrm{~mm}$, up to a year of $11.23 \pm 0.37 \mathrm{~mm}$, at the age of 4-6 years $-14,15 \pm 0.51 \mathrm{~mm}$, and the size of the spinal cord was: $5.45 \pm 0.26 \mathrm{~mm}, 5.63 \pm 0.26 \mathrm{~mm}$ and $7.32 \pm 0.42 \mathrm{~mm}$, respectively. Ultrasonographically, the width between LM varied from 15.4 to $18.05 \mathrm{~mm}$, in children with neurological symptomatology (NS) averaged $17.3 \pm 0.9 \mathrm{~mm}$, and in the subgroup without NS $-16.3 \pm 0.8 \mathrm{~mm}$, in the comparison group (CG) - $16.2 \pm 0.7 \mathrm{~mm}$, without significant differences. The average value of D1 for children with NS was $4.4 \pm$ $0.3 \mathrm{~mm}$, without NS, $4.6 \pm 0.4 \mathrm{~mm}$, and for CG $-5.3 \pm 0.4 \mathrm{~mm}$. The value of D2 was significantly different $(P<0.05)$ between the children with NS $(7.6 \pm 0.7 \mathrm{~mm})$, without NS $(6.8 \pm 0.5 \mathrm{~mm})$, and for CG $(5.9 \pm 0.4 \mathrm{~mm})$. The D1/D2 index in the groups was $0.6 \pm 0.07 ; 0.7 \pm 0.04$ and $0.9 \pm 0.08$, respectively. At the same time, the difference in the value of the D1/D2 index between newborns with AARS of both subgroups and healthy children had a high statistical significance $(p<0.001)$. The degree of asymmetry of the position of OP with respect to LM in health newborns varied within the range of $6.9-15.1 \%$ and averaged $11.0 \pm 4.1 \%$. In the subgroup of children with AARS and NS, this indicator was $71.79 .5 \%$, without NS $-46.6 \pm 8.3 \%(p<0.001)$. Moderate asymmetry in the range of $21-40 \%$ among children with NS was observed in $15.4 \pm 10.4 \%$, and without NS - in $60.0 \pm 13.1 \%$ of cases $(p<0.01)$. 
Expressed asymmetry over $40 \%$ among children with NS was observed in $84.6 \pm 10.4 \%$, and without NS - in $40.0 \pm$ $13.1 \%$ of cases $(p<0.01)$.

Conclusion: The ultrasound symptoms of the rotational subluxation of the atlas in children are: the asymmetry of the odontoid process relative to the lateral masses of more than $1 \mathrm{~mm}$ or $20 \%$, the decrease in the gap between the odontoid process and the transverse ligament of less than $1 \mathrm{~mm}$, the irregularity of the thickness of the transverse ligament, the asymmetry of the thickness of the pterygoid ligaments. Signs of a severe form of the rotational subluxation of the atlanta - the asymmetry of the odontoid process with respect to the lateral masses of more than $2.0 \mathrm{~mm}$ (or more than $60 \%$ ), the D1/D2 index is less than 0.60 , the absence of visualization of the gap between the odontoid process and the transverse ligament, deformation of the anterior dural space with the presence of a hyperechoic mass in it, an increase in the dimension of the posterior dural space.

Keywords: Traumatic; Radiography; Ultrasonography; Neurological

\section{Introduction}

Traumatic damage to bones and joints in children is an actual problem. The ratio of child and adult traumatism is $1: 3-5$. Traumatic damage to the cervical spine in further lead to the development of degenerative dystrophic changes that can be the cause of clinical manifestations, in particular neurological symptoms. Cervical injury accounts for $25 \%$ to $30 \%$ of all spinal injuries and $1 \%$ to $4 \%$ of all injuries [1]. Among the traumatic injuries of atlantoaxial joint (AAJ) in children, a rotational subluxation in the C1-C2 segment is more common. The frequency of its occurrence in children under 10 years varies from 34 to $73 \%$, in newborns this injury is the most frequent among all spinal injuries (up to 54\%) [2,3].

The exact mechanism Injuries of the cervical spine are not defined, they are often multiple. The most common mechanisms of injuries are flexion (46-79\%), extension (20-38\%), flexion-rotational (12\%), compression (12\%), hypertension with lateral rotation (4-6\%). Despite the fact that the anatomy of the cervical region allows its movement in all planes, flexion-extensor movements are dominant. The position of the head and neck during the impact, as well as the direction of the traumatic force, play an important role in the mechanism of injury. In newborns, the main mechanism of the rotational subluxation of Atlanta is a birth trauma, and in children of younger and older age it is a domestic, road transport and sports equipment. In the emergence of Atlanto-axial rotary subluxation (AARS), in addition to the nature and mechanism of injury, the presence of dysplasia of the elements of the Atlanto-axial articulation (AAA) and the odontoid process (OP) plays an important role, lateral masses (LM), pterygoid ligaments (PL). However, these findings may not be applicable to children because of different injury patterns and greater anatomic variability. Normally, hyperflexion is limited to the integument membrane, and hyperdisplay by the front arch of $\mathrm{C} 1$, resting on the OP. LM limit the excessive rotational movements. When extension in the upper cervical region occurs without a rotational component, this can lead to anterior dislocation of AAA [4-6].

Although it was originally thought to be a congenital lesion due to a failure of the centre of ossification of the dens to fuse with the body of $\mathrm{C} 2$, it may actually represent an unremembered and/or unrecognised fracture through the $\mathrm{C} 2 /$ dens growth plate before the age of 5 or 6 . There may be associated instability and chronic symptoms [7].

Plain radiography might serve as an effective screening test that reduces exposure to potentially dangerous ionizing radiation. In adult studies, cervical spine radiography had a sensitivity for cervical spine injury of $80 \%$ for a single cross-table lateral view and of greater than $90 \%$ for a 3 -view series. [8].

Cervical spine injury, although very rare in children, has potentially devastating consequences. After suffering blunt trauma requiring emergency department evaluation, many children undergo radiological evaluation as part of the process of cervical "clearance," which may include cervical spine radiographs and/or cervical spine computed tomography (CT). The estimated amount of ionizing radiation exposure is 30 -fold higher for cervical spine CT than plain cervical spine radiography (approximate dose of ionizing radiation 6 vs $0.2 \mathrm{mSv}$ ) [9].

Radiography remains the main, most common method for diagnosing RPA (atlanto-axial rotary subluxation). However, in the visualization of soft tissue structures, in particular in newborns, due to the lack of complete ossification of the Cruevelle joint and the OP, their full visualization is limited. MRI is the best method of visualization of the spinal cord and AAS ligament apparatus when used magnetic fields above $0.36 \mathrm{~T}$ [10]. Ultrasound examination (US) also makes it possible to visualize OP, ligamentous apparatus, spinal cord, dural space [11].

\section{Objective}

The aim of the study was to evaluate the possibilities of B-mode Ultrasonography in diagnosing the atlanto-axial rotary subluxation (AARS).

\section{Materials and Methods}

Our survey was based on 28 (45.2\%) newborns (Group I) and 34 (54.8\%) children aged 4-6 years (Group II) who were diagnosed with AARS as a result of birth and mechanical trauma, respectively. The comparative group (CG) comprised 50 children - of them 12 newborns, 15 - under the age of 1 year, 23 - at the age of 4-6 years. Everyone children were given radiography, ultrasound and only 12 (19.3\%) of them - MRI.

Radiographs of the upper cervical spine were performed in a direct sighting projection with an open mouth in children older than 2 years (in newborns - in a direct projection) and in the lateral projection. In addition to visual assessment of X-ray measurements were made of Xray diffraction measurements of the OP width, the distance between the LM C1, the distance from the OP to the LM from two sides, the width anterior atlanto-axial joint (Cruvellus joint).

Ultrasound was performed for all children in sagittal and axial sections using linear and microconvex sensors with a frequency of 5-10 and 4-9 MHz using color and energy Doppler mapping in real time. Echography of the upper cervical region allowed from the anterolateral access to carry out one-stage visualization from 2 to 4 by a 
Citation: Abdullaeiv RY, Sharmazanova EP, Voronzhev IA, Abdullaev RR (2017) Assessment of the Possibilities of B-Mode Ultrasonography in the Diagnosis of Atlanto-Axial Rotary Subluxation in Children. J Spine 6: 393. doi:10.4172/2165-7939.1000393

Page 3 of 6

number of located vertebrae with evaluation of their shape, position of the OP, contents of the spinal canal. From the rear access in the axial section, the position of the OP relative to the LM was determined, the state of the transverse ligament was assessed. The distance from the edge of the OP to the inner LM surface on both sides. The smallest value of this distance was denoted by D1, the largest by D2. Normally the difference between D2 and D1 did not exceed $0.5 \mathrm{~mm}$. The degree of asymmetry was estimated by the formula:

D2-D1/D1 $\times 100 \%$, and normally ranged from $7 \%$ to $15 \%$.

\section{Results and Discussion}

According to the X-ray data, in norm in newborns $\mathrm{C} 1$ has cores of ossification of LM triangular shape with rounded contours and 2 nuclei of ossification in the posterior arc (Figure 1). Sometimes neonates have a nucleus of ossification in the anterior arc C1 (40.9\%). In the presence of a nucleus of ossification in the anterior arc, the width of the x-ray slit of the anterior-atlas-axial joint was $1.5-2.0 \mathrm{~mm}$, and the nucleus of ossification was parallel to the OP. The main criterion of the norm for AAA was the central location of the OP in relation to the LM. The average distance between the LM at $\mathrm{C} 1$ level in newborns was $16.19 \pm 0.78 \mathrm{~mm}$, in children under 1 year of age it was $18.01 \pm 1.08 \mathrm{~mm}$, at the age of $4-6$ years $-27.87 \pm 0.98 \mathrm{~mm}$ (Figure 1).
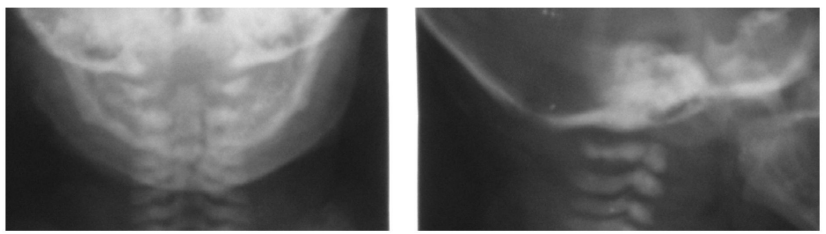

Figure 1: Radiographs of the cervical spine in a straight and lateral projection in a newborn (17 days) with visualization of a normal Atlanto-axial articulation.

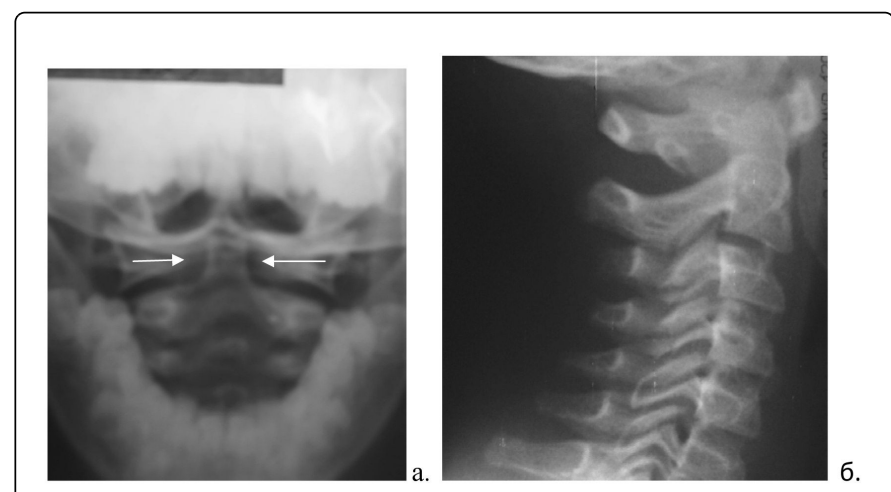

Figure 2: X-ray of the 5-year-old child in a direct projection through the open mouth (a) and lateral projection (b) to visualize the atlanto-axial articulation (the dentate process occupies the central position (arrows).

At the age of up to 1 year, the bodies and arcs of the vertebrae retain the degree of ossification that they have at the end of the intrauterine development. At the age of 1 to 3 years, the frontal and posterior arcs of the atlas are fused, its anterior tubercle is clearly pronounced and has the shape of an elongated oval with thickened end plates.
The shape of the odontoid process $\mathrm{C} 2$ corresponds to the anatomical process, its height is 1.5 times the height of the vertebral body. At the age of 4-6 years, the image of $\mathrm{C} 1$ completely corresponds to its image in adults (Figure 2). During this age period there is complete ossification of the tooth $\mathrm{C} 2$ and its fusion with the vertebral body.

In the lateral projection, apart from the Crucellus joint, the width of the retro-tracheal space was determined, which is $4.5 \pm 2 \mathrm{~mm}$ at the C1-C3 level, the posterior wall of the larynx and the trachea is normally even, parallel to the vertebral bodies (Figure 3).

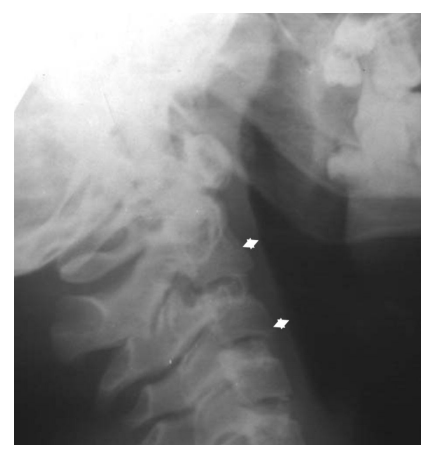

Figure 3: Evaluation of retro-tracheal space on the roentgenogram in the lateral projection (arrows).

With the help of ultrasound, the ligaments of the atlanto-axial segment were studied. The thickness of the transverse ligament (TL) averaged $1.92 \pm 0.14 \mathrm{~mm}$ - in neonates, $2.31 \pm 0.17 \mathrm{~mm}$ - in children under 1 year and $2.69 \pm 0.24 \mathrm{~mm}$ in children $4-6$ years. The thickness of the synovial bag (gap) between the OP and TL was normally more than $1.5 \mathrm{~mm}$. Echogenicity of TL in newborns was reduced and comparable with the echogenicity of the spinal cord, in children 4-6 years old - with the pulpous nucleus of the intervertebral disc (Figure 4).
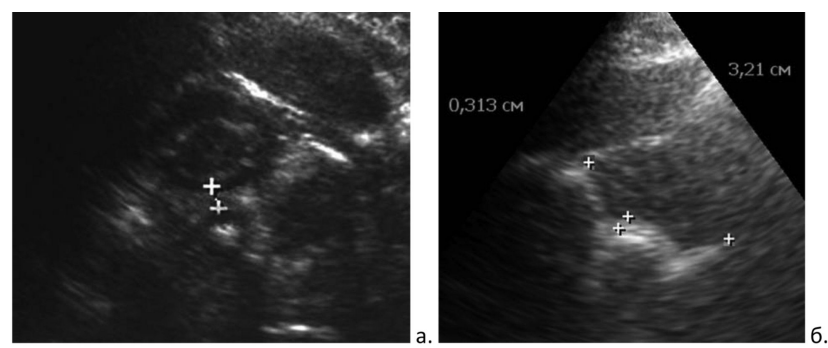

Figure 4: Ultrasonic tomogram of the newborn's neck (7 days) at the level of C1-C2 (a): the spinal cord is defined in the center of the image. Crosses denote a transverse ligament in the form of a hypoisoechoic horizontally located structure, followed by a hyperechoic structure - a dentate process. The same for a child of 5 years (b): measured the thickness of the transverse ligament, its echogenicity is higher than that of a newborn; Between LM and OP is visualized synovial bag.

Visualization of the cruciform and pterygoid ligaments is carried out in several stages: first, images of the dentate process in the cross section, then in the longitudinal section, then turning the sensor at an 
Citation: Abdullaeiv RY, Sharmazanova EP, Voronzhev IA, Abdullaev RR (2017) Assessment of the Possibilities of B-Mode Ultrasonography in the Diagnosis of Atlanto-Axial Rotary Subluxation in Children. J Spine 6: 393. doi:10.4172/2165-7939.1000393

Page 4 of 6

angle of 40-60 degrees relative to the longitudinal axis of the OP (Figure 5).

Cruciform ligament (CL) on the echogram had a medium-low echogenicity, an even contour and a thickness of $1.6 \mathrm{~mm}$ to $2.5 \mathrm{~mm}$, and an average of $1.83 \pm 0.17 \mathrm{~mm}$ in newborns, $2.14 \pm 0.15 \mathrm{~mm}$ in children 1 year and $2.35 \pm 0.21 \mathrm{~mm}-$ in $4-6$ years.
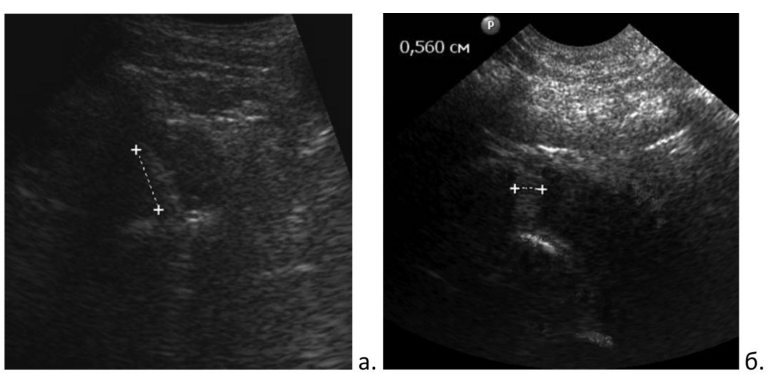

Figure 5: Visualization of the cruciate ligament (a) and pterygoid ligament (b).

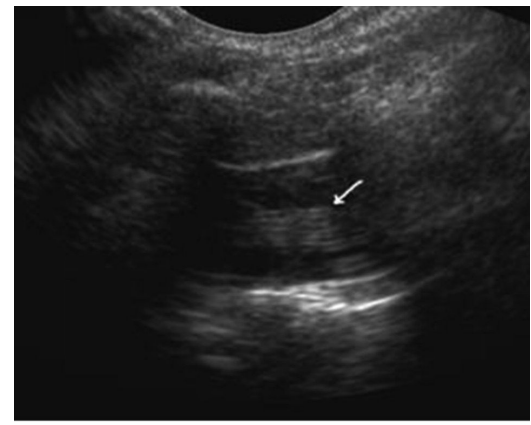

Figure 6: Visualization of the spinal cord (arrow) in a 4-year-old child from an ante-lateral approach in the longitudinal projection.

On the axial ultrasound, the anterior-posterior dimension of the dural sac, the vertebral canal and the spinal cord was determined (Figure 6,7).

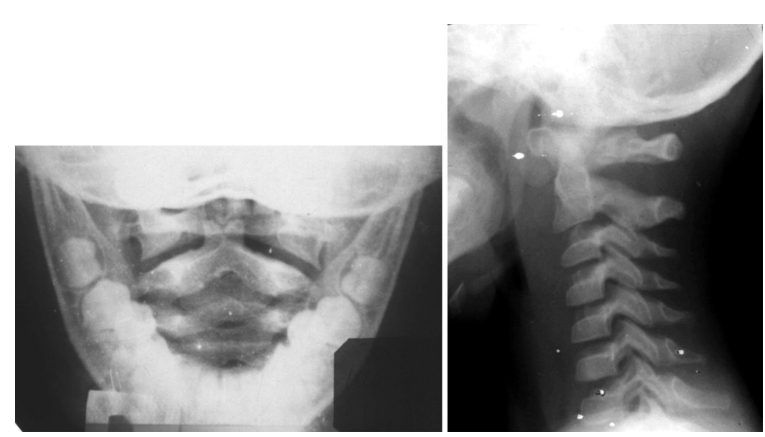

Figure 7: Rotational subluxation of the Atlanto in patient 4-yearsold.

In newborns, X-ray signs of AARS did not differ from those of older children (Figure 8).

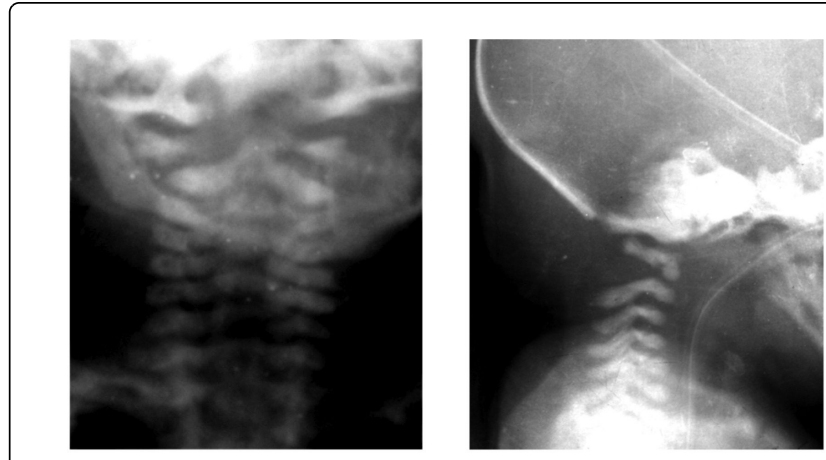

Figure 8: Rotational subluxation of the atlas in a newborn.

According to our data, the sagittal size of the spinal canal at the C1C2 level in the group of newborns was $10.04 \pm 0.42 \mathrm{~mm}$, up to a year of $11.23 \pm 0.37 \mathrm{~mm}$, at the age of $4-6$ years $-14,15 \pm 0.51 \mathrm{~mm}$, and the sagittal size of the spinal cord (C1-C3) was $-5.45 \pm 0.26 \mathrm{~mm}, 5.63 \pm$ $0.26 \mathrm{~mm}$ and $7.32 \pm 0.42 \mathrm{~mm}$, respectively.

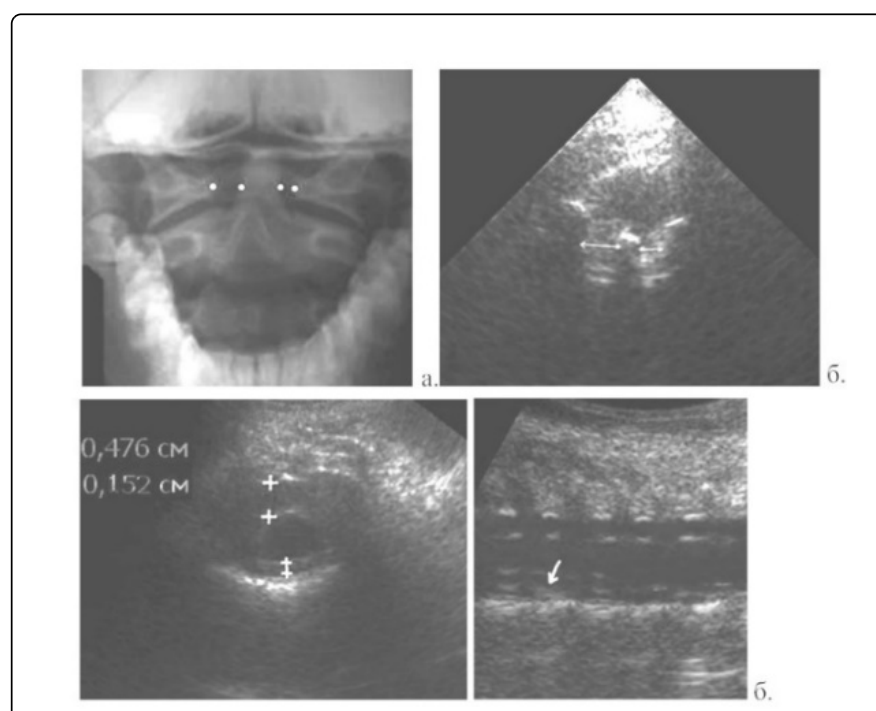

Figure 9: Rotational subluxation in a 6-year-old child on the roentgenogram (a) and on ultrasound tomograms (b).

The radiological diagnosis of the rotational subluxation of the atlas was based on the detection:

- The asymmetric position of the OP of the second cervical vertebra (C2) with respect to the LM more than $1 \mathrm{~mm}$ (the "displacement" of the OP is carried out in the direction of subluxation);

- Different width of the slits of the lateral atlanto-axial joints;

- Ustupopodobnogo displacement of articular surfaces of lateral atlanto-axial joints;

- The widening of the anterior-axial joint anterior joint (Cruvelier joint) is larger than $2 \mathrm{~mm}$, with the ossification core of the anterior $\operatorname{arc} \mathrm{C} 1$;

- The formation of an angle between the rear $\operatorname{arcs} \mathrm{C} 1$ and C2;

- Torticollis;

- An increase in the retrofaringeal space at the $\mathrm{C} 2$ level. 
Citation: Abdullaeiv RY, Sharmazanova EP, Voronzhev IA, Abdullaev RR (2017) Assessment of the Possibilities of B-Mode Ultrasonography in the Diagnosis of Atlanto-Axial Rotary Subluxation in Children. J Spine 6: 393. doi:10.4172/2165-7939.1000393

Page 5 of 6

Ultrasonography confirmed the radiological symptoms of AARS and obtained additional information on changes in the ligamentous apparatus (Figure 9).

Ultrasonographically, the width between LM varied from 15.4 to $18.05 \mathrm{~mm}$, in children with neurological symptomatology (NS) averaged $17.3 \pm 0.9 \mathrm{~mm}$, and in the subgroup without NS - $16.3 \pm 0.8$ $\mathrm{mm}$, in the comparison group - $16.2 \pm 0.7 \mathrm{~mm}$, while there were no significant differences. The average value of D1 for children with NS was $4.4 \pm 0.3 \mathrm{~mm}$, in the group of children without NS, $4.6 \pm 0.4 \mathrm{~mm}$, and for CG $-5.3 \pm 0.4 \mathrm{~mm}$. D2 value was significantly different in children with NS $-7.6 \pm 0.7 \mathrm{~mm}(\mathrm{P}<0.05)$, in the group of children without NS $-6.8 \pm 0.5 \mathrm{~mm}$, and for SG $-5.9 \pm 0.4 \mathrm{~mm}$. The D1/D2 index in the groups was $0.6 \pm 0.07,0.7 \pm 0.04$ and $0.9 \pm 0.08$, respectively. At the same time, the difference in the value of the D1/D2 index between newborns with RPA of both subgroups and healthy children had a high statistical significance $(\mathrm{p}<0.001)$
In the group of healthy children, the difference between the values of D2 and D1 varied within 0.4-0.6 mm. We calculated the degree of asymmetry of the position of OP with respect to LM by the formula: Д2-Д1/Д1 $\times 100 \%$, which normally varied within the range of $6.9-15.1 \%$ and averaged $11.0 \pm 4.1 \%$. In the subgroup of children with AARS and NS, this indicator was $71.7 \pm 9.5 \%$, without NS $-46.6 \pm$ $8.3 \%$, which was significantly $(\mathrm{p}<0.001)$ higher than in the comparison group, and the difference between the newborn subgroups was minimal $(\mathrm{p}<0.05)$.

Table 1 presents ultrasonography data on the state of AAA in newborns with AARS, depending on the severity of the clinical symptoms.

The degree of asymmetry of the odontoid process is divided into 3 degrees: less than $20 \%$, from 21 to $40 \%$ and over $40 \%$.

\begin{tabular}{|c|c|c|c|}
\hline Ultrasonographic parameters & $\begin{array}{l}\text { Newborns with neurological } \\
\text { symptoms } \\
(n=13)\end{array}$ & $\begin{array}{l}\text { Newborns without neurologic } \\
\text { symptoms } \\
(n=15)\end{array}$ & $\begin{array}{l}\text { Newborns } \\
\text { (Comparative group) } \\
\text { ( } n=12)\end{array}$ \\
\hline Width between lateral masses & $17.13 \pm 0.92 \mathrm{~mm}$ & $16.25 \pm 0.83 \mathrm{~mm}$ & $16.19 \pm 0.78 \mathrm{~mm}$ \\
\hline D1 & $4.42 \pm 0.36 \mathrm{~mm}$ & $4.63 \pm 0.39 \mathrm{~mm}$ & $5.29 \pm 0.37 \mathrm{~mm}$ \\
\hline $\mathrm{D} 2$ & $7.59 \pm 0.68 \mathrm{~mm}$ & $6.79 \pm 0.52 \mathrm{~mm}$ & $5.87 \pm 0.41 \mathrm{~mm}$ \\
\hline D1/D2 & $0.58 \pm 0.07^{\star \star *}$ & $0.68 \pm 0.04^{\star \star \star}$ & $0.90 \pm 0.08$ \\
\hline Width of tooth-shaped process & $5.12 \pm 0.34 \mathrm{~mm}$ & $4.83 \pm 0.35 \mathrm{~mm}$ & $5.03 \pm 0.36 \mathrm{~mm}$ \\
\hline $\begin{array}{l}\text { The degree of asymmetry of the tooth-shaped process } \\
\text { relative to the lateral masses }\end{array}$ & $71.7 \pm 9.5 \%$ *** & $46.6 \pm 8.3 \%$ *** & $11.0 \pm 4.1 \%$ \\
\hline Asymmetry of the tooth-shaped process $<20 \%$ & - & - & $100.0 \pm 8.3 \%$ \\
\hline Asymmetry of the tooth-shaped process $21 \%$ to $40 \%$ & $15.4 \pm 10.4 \%$ ** & $60.0 \pm 13.1 \%$ & - \\
\hline Asymmetry of the tooth-shaped process $>40 \%$ & $84.6 \pm 10.4 \%$ ** & $40.0 \pm 13.1 \%$ & - \\
\hline
\end{tabular}

Table 1: Ultrasonographic parameters of newborns with a Atlantoaxial rotary subluxation.

In the comparison group in all children, the degree of asymmetry of the OP was less than $20 \%$. Moderate asymmetry in the range of $21-40 \%$ among children with NS was observed in $15.4 \pm 10.4 \%$, and without NS - in $60.0 \pm 13.1 \%$ of cases $(\mathrm{p}<0.01)$. Expressed asymmetry over $40 \%$ among children with NS was observed in $84.6 \pm 10.4 \%$, and without NS - in $40.0 \pm 13.1 \%$ of cases $(p<0.01)$.

Thus, the asymmetry of OP with respect to LM with a value of more than $40 \%$ in children with AARS is more often accompanied by a clinically significant neurological symptom.

\section{Conclusion}

The ultrasound symptoms of the rotational subluxation of the atlas in children are: the asymmetry of the odontoid process relative to the lateral masses of more than $1 \mathrm{~mm}$ or $20 \%$, the decrease in the gap between the odontoid process and the transverse ligament of less than $1 \mathrm{~mm}$, the irregularity of the thickness of the transverse ligament, the asymmetry of the thickness of the pterygoid ligaments. Signs of a severe form of the rotational subluxation of the Atlanta - the asymmetry of the odontoid process with respect to the lateral masses of more than $2.0 \mathrm{~mm}$ (or more than $60 \%$ ), the D1/D2 index is less than 0.60 , the absence of visualization of the gap between the odontoid process and the transverse ligament, deformation of the anterior dural space with the presence of a hyperechoic mass in it, an increase in the dimension of the posterior dural space.

\section{References}

1. McCall T, Fassett D, Brockmeyer D (2006) Cervical spine trauma in children: a review. Neurosurg Focus 20: 1-8.

2. Spouzjak MI, Sharmazanova OP (2000) X-ray diagnostics traumatic injuries of the cervical spine in children. Ukrainian Radiological Journal 3: 291-297.

3. Platzer P, Jaindl M, Thalhammer G, Dittrich S, Kutscha-Lissberg F, et al. (2007) Cervical spine injuries in pediatric patients. J Trauma 62: 389-396.

4. Lustrin ES, Karakas SP, Ortiz AO, Cinnamon J, Castillo M, et al. (2003) Pediatric cervical spine: Normal anatomy, variants, and trauma. Radiographics 23: 539-560. 
Citation: Abdullaeiv RY, Sharmazanova EP, Voronzhev IA, Abdullaev RR (2017) Assessment of the Possibilities of B-Mode Ultrasonography in the Diagnosis of Atlanto-Axial Rotary Subluxation in Children. J Spine 6: 393. doi:10.4172/2165-7939.1000393

Page 6 of 6

5. Khanna G, El-Khoury GY (2007) Imaging of cervical spine injuries of childhood. Skeletal Radiol 36: 477-494.

6. Warner WC, Hedequist DJ (2015) Cervical Spine injuries in Children. In: Beaty J., Kasser J., eds. Fractures in Children. Vol 1. 8th ed. Philadelphia, PA: Lippincott Williams \& Wilkins, pp: 845-898.

7. Hedequist D, Hresko T, Proctor M (2008) Modern cervical spine instrumentation in children. Spine 33: 379-383.

8. Mower WR, Hoffman JR, Pollack CV Jr, Zucker MI, Browne BJ, et al. (2001) Use of plain radiography to screen for cervical spine injuries. Ann Emerg Med 38: 1-7.
9. Chan PN, Antonio GE, Griffith JF, Yu KW, Rainer TH, et al. (2005) Computed tomography for cervical spine trauma. The impact of MDCT on fracture detection and dose deposition. Emerg Radio 11: 286-290.

10. Geck NJ, Yoo S, Wang JC (2001) Assessment of cervical ligamentous injury in trauma patients using MRI. J Spinal Disorders 14: 371-377.

11. Abdullaev RY, Tahar M (2010) Ultrasonography of the upper cervical spine in children: methodological aspects and normal anatomy. Ukrainian Radiological Journal 1: 54-58. 